DOI: 10.20472/IAC.2018.039.037

CHRISTINA PLATZ

Royal Melbourne Institute of Technology/ RMIT University, Australia

\title{
THE COPYRIGHT CRISIS: THE SOCIAL NECESSITY OF THE RENEGOTIATION OF THE TPP AND THE RISE OF THE CPTPP
}

\begin{abstract}
:
Copyright law is continuously in a crisis, however, on 8 March 2018, a new initiative, the Comprehensive and Progressive Agreement for Trans-Pacific Partnership (CPTTP) emerged at the international level in order to aid trade related challenges such as copyright law. The CPTPP agreement was the result of an extensive renegotiation of the Trans-Pacific Partnership Agreement (TPP) that since the US departure in January 2017 had been considered dead in the water.

This article considers the reasoning for the renegotiation of the TPP from the perspective of Australian society with focus on copyright law. It utilises the theoretical underpinning of cooperation theory as well as case studies of the Australia-United States Free Trade Agreement (AUSFTA) and the TPP to examine why it was necessary to renegotiate the TPP and significantly cut back on the IP chapter.

This article concludes that it was necessary to renegotiate the TPP because it represented the US copyright agenda and failed to satisfy the Australian interests in copyright law and promote the copyright balance.
\end{abstract}

\section{Keywords:}

Copyright law, trade agreement, technology, intellectual property

JEL Classification: 030 